\title{
Intelligence and economic sophistication
}

\author{
Athanasios Lapatinas ${ }^{1,2} \cdot$ Anastasia Litina ${ }^{2}$ \\ Received: 5 November 2016 / Accepted: 5 June 2018 / Published online: 26 June 2018 \\ (c) The Author(s) 2018
}

\begin{abstract}
Backed by strong empirical results, obtained from several different specification and sensitivity analyses, this paper contends that countries with high-intellectual quotient populations produce and export more sophisticated/complex products. This result is further reinforced by the quality of democracy.
\end{abstract}

Keywords Intelligence · Economic sophistication · Complexity · Democracy · Institutions

JEL Classification F1 - A13 - D2 - B52

\section{Introduction}

Recent works by Hidalgo et al. (2007) and Hidalgo and Hausmann (2009) explain economic development and growth as a process of information development, a process of learning how to produce and export more complex products. In this paper, we argue that the development path of a country lies in its capacity to accumulate the "knowledge" part of the Robert Solow's growth model. "Knowledge" is required to produce varied and more sophisticated goods; moreover, embedded in the countries" productive structures, "knowledge" explains the differences in their economic performance (Rodrik 2006; Saviotti and Frenken 2008; Cristelli et al. 2015).

The question though is how "knowledge"-rich products and services are created in the economy. Hidalgo (2015) argues that what Kuznets called "measure of our ignorance" in his Nobel Prize acceptance speech is actually our individual mental capacity, our "personbytes", or to put it broadly, our intelligence. A central function of the

Electronic supplementary material The online version of this article (https://doi.org/10.1007/s00181-018 $-1511-y)$ contains supplementary material, which is available to authorized users.

$\bowtie$ Athanasios Lapatinas

athanasios.lapatinas@ec.europa.eu

1 European Commission, Joint Research Centre, Via E. Fermi 2749, TP 361, 21027 Ispra, VA, Italy

2 Department of Economics, University of Ioannina, P.O. Box 1186, 45110 Ioannina, Greece 
economies then is to grind people's "personbytes" in producing sophisticated/complex products. And because such processes are enabled (or hindered) by inclusive (or extractive) institutions, the differences in the countries' capacities to chop up, process and reassemble their people's collective intelligence is what makes some countries more developed than others.

In this paper, we attempt to quantify the relationship between intelligence and sophistication. We empirically establish that collective intelligence is indeed related to a more sophisticated product space and that besides having a direct positive effect on economic growth (e.g., Weede and Kämpf 2002; Jones and Schneider 2006), intelligence has an indirect beneficial effect on a country's growth through the country's "knowledge"-endowment that is required to produce varied, sophisticated goods.

Furthermore, we find that this indirect effect is reinforced by the presence of democratic institutions. We explore the differential effect of intelligence on sophistication for different levels of institutions as motivated by the analysis in Hidalgo (2015) who emphasizes that different countries give different abilities to its people to develop, secure and organize the information they have. One plausible example is property rights, and how securing them allows one to further develop an idea or a patent. To make the example even more extreme, one can think of regimes in which some groups in the society, e.g., women or immigrants, do not even have access to an initial set of information that can lead to the further development of information and thus of more sophisticated structures or products. It is interesting to note that even in developed countries, such as Scandinavian countries, there is a huge effort to secure equal participation of men and women in the labor market. This is not only done for human rights purposes but it is also crucial for the smooth functioning of the economy and for exploiting all its available resources equally. Thus, institutional quality may make a difference to the speed of transition from the "personbyte," which is the individual capacity of a single individual to the "firmbyte," which indicates the knowledge distributed in a network of firms.

It is thus argued that the economic analysis should be interested not only in enhancing cognitive skills and information growth but also in how they interact with the functioning of economic and political institutions. This work has sobering messages for policy makers as well. First, that collective intelligence is necessary for economic development, through improving the diversity and refinement of the economy's export structure. Thus, identifying the policies that can raise collective intelligence is a firstorder issue. Second, that the diverse effects of collective intelligence are larger in the presence of well-functioning institutions that govern all aspects of a country's economic and social life. Incentives arising from institutional functioning and economic policies are important accelerators of the accumulation of "knowledge" and of the extent to which existing human capital endowments are utilized in production.

The rest of the paper proceeds as follows; in Sect. 2, we discuss the relevant literature upon which we base our empirical analysis; in Sect. 3, we elaborate on a theoretical framework that links intelligence and sophistication; in Sect. 4, we discuss the empirical methodology and the data; in Sect. 5, we present the empirical results. Finally, Sect. 6 concludes. 


\section{Related literature}

The aim of the paper is to empirically establish and to quantify the link between intelligence and product sophistication, a link that is totally unexplored in the existing literature. Second, we want to draw policy implications by arguing that the positive effect of intelligence is further reinforced by the presence of high institutional quality.

Starting from the topic of intelligence, the existing literature that employs intelligence as an explanatory variable is rapidly expanding recently and has come up with various diverse and interesting results. ${ }^{1}$ A natural starting point was the positive link between intelligence and per capita real GDP as suggested by the pioneering studies of Lynn and Vanhanen $(2002,2006)$, who first complied and used the intellectual quotient (IQ) data for several countries. They established that countries whose citizens have higher average scores on intelligence tests tend to be more economically developed, institutionally advanced and prosperous. This finding spurred economists to employ the IQ data in many subsequent published studies further investigating the relationship between intelligence and per capita income (e.g., Meisenberg 2004, 2009, 2012; Dickerson 2006; Rindermann 2008a, b, 2012; Jones and Schneider 2006; Templer 2008). Some researchers extended the analysis to explore the link between intelligence and economic growth (see e.g., Rindermann 2008a, b; Meisenberg 2012) also finding a positive relationship.

Another strand of the literature placed the spotlight on the interplay between intelligence and institutions. Several studies have established a positive correlation between intelligence and institutional development, democracy and economic/political freedom (see e.g., Meisenberg 2004, 2009; Rindermann 2008a, b; Jones 2011; Kanyama 2014).

Several other outcome variables have been linked to intelligence such as income inequality (Kanazawa 2009; Meisenberg 2012), education and literacy (Barber 2005), corruption (Meisenberg 2004, 2012; Potrafke 2012), savings (Jones and PodemskaMikluch 2010), investment (Ram 2007), employment (Vinogradov and Kolvereid 2010), poverty (Kodila-Tedika and Bolito-Losembe 2014), financial development (Kodila-Tedika and Asonglu 2015), happiness (Stolarski et al. 2015), religiosity (Reeve 2009), liberalism (Kanazawa 2009) and entrepreneurship (Hafer and Jones 2015).

To summarize the spirit of the findings of the above-mentioned literature that employs the Lynn and Vanhanen measures of intelligence, it is overall argued that intelligence is a robust predictor of economic, social and political development as this is measured with a wide set of indicators. This result is robust across a large sample of countries.

On the other hand, and focusing on the topic of product sophistication, our contribution lies in bridging the intelligence literature with the literature that emphasizes the importance of economic complexity for the economy as a whole. The literature on economic complexity is another crucial literature that shows that the diversity, the number and the ubiquity of the products exported by a country are a good indicator of the level of sophistication of a country's productive structure.

\footnotetext{
1 The associated literature is rather extensive. In this section, we provide an overview of only a fraction of this literature. In Appendix, we provide a more comprehensive list of papers that explore similar research questions but employ different methodologies/specifications.
} 
The topic of economic complexity is a rather new one, and research studies on this area are rather limited so far, as well as its use in economics. The vast majority of the literature analyzes primarily the properties of the index (e.g., Hausmann and Hidalgo 2014; Albeaik et al. 2017a, b). There are few studies that have linked economic complexity with economic outcomes such as development, institutions and income inequality, suggesting that higher level of economic sophistication is associated with higher economic development (see e.g., Felipe et al. 2012; Caldarelli et al. 2012; Cristelli et al. 2015; Hausmann et al. 2007; Hidalgo et al. 2007)

Our study is the first one to bring together these two strands of literature and to empirically show that IQ is a significant determinant of product sophistication. To the extent that the creation of a new product embeds, among other things, not only the use of existing information but also the creation of new information, exploring whether IQ is a determinant of product sophistication arises naturally as a question worth pursuing. Crucially, we further show that even countries with high level of intelligence can benefit from the presence of good-quality institutions. ${ }^{2}$

\section{Theoretical framework}

As already mentioned in the section above, the literature that links IQ with a range of economic and social outcomes is quite widespread. What is less known is the measure of economic complexity that is reflecting the degree of economy's product sophistication and its economic implications.

Few things should be thus mentioned about this index that will crystallize the rational beyond empirically exploring the relationship between intelligence and sophistication. While the definition of the measure of economic complexity is rather simple (i.e., the diversity, the number, and the ubiquity of products a country exports, as already mentioned in the introduction), the actual measure is much more sophisticated than its definition. What is crucial is that what is embedded in this measure is information, i.e., accumulation of knowledge and know-how. For instance, each product an economy exports is associated with some level of complexity and sophistication that makes it unique. Moreover, it is not only the information that is embedded in a product that matters but also the order under which all this information is put together. Hidalgo (2015) characteristically mentions that an expensive car is not only a sum of its parts but also the way that these parts have been put together.

This is the "physics" behind information. However, there is also an economic part behind information and its implications. As it has always been the case in economics, the economic part lies in the fact that information is not free and is not limitless. It depends upon a multitude of factors, and this is what drives the differences between countries. It can depend upon human capital, natural resources, the institutional setting or geographical location. Thus, the economy's productive capacity depends on its ability to gather, combine and, perhaps, even secure all the necessary information needed to design and produce a product.

\footnotetext{
2 The crucial role of institutions has been emphasized already in the economics literature (Acemoglu and Robinson 2012).
} 
This intuition is what drives the first part of our empirical analysis. Given the information's importance for the production of complex goods and thus for an increase in the overall level of an economy's sophistication, we attempt to shed more light on its determinants. The IQ-related literature has found that it is linked to educational attainment, educational inputs and various cognitive outputs, like patents, scientific and technological excellence, academic publications, and Nobel prizes in science among other outcomes. All these are types of information that can lead to a high level of economic sophistication in terms of economy's productive capacity. Thus, exploring the link between the average level of intelligence and product sophistication seems like a natural place to start. Given that the correlation between IQ and all the abovementioned outcomes is reported to be positive and robust, it can be plausibly assumed that IQ may confer a positive effect on the economy's level of sophistication. At the same time, the advantage of IQ is that it is a rather broad measure that encompasses most of the measures mentioned above. We can thus get a generalized result with many varying policy implications.

\subsection{IQ as a determinant of economic complexity}

Motivated by the theoretical discussion on the determinants of the index, in this subsection we model the hypothesis to be tested. To study the relationship between intelligence and product sophistication, we first construct the measure of economic sophistication (EXPY) using the framework developed by Hausmann et al. (2007). This index captures the productivity level associated with a country's export, i.e., it is a proxy for the most productive set of products the country can produce at a given time. In order to calculate the EXPY, index goods are ranked according to the income levels of the countries that export it. Products exported by prosperous countries are ranked higher than products exported by poor countries. The aggregation of these productlevel calculations leads to the country-wide indexes of economic sophistication.

In detail, let us assume that $j$ denotes the country and $k$ the product. Then total exports of product $k$ from country $j$ equal:

$$
X_{j}=\sum_{k} x_{j k}
$$

If $(Y / L)_{j}$ denotes the per capita GDP of country $j$, the productivity level associated with product $k$ equals the weighted average of per capita GDPs, where the weights represent the Revealed Comparative Advantage ( $R C A)$ of each country in that product:

$$
\operatorname{PRODY}_{k}=\sum_{j} \frac{\left(\frac{x_{j k}}{X_{j}}\right)}{\sum_{j}\left(\frac{x_{j k}}{X_{j}}\right)}(Y / L)_{j}
$$

Then, the PRODY metric can be used to compute the productivity level associated with country $i$ 's economic sophistication, $\mathrm{EXPY}_{i}$, as the average income and productivity level associated with all products exported by a country. It is computed as the 
weighted average of all relevant PRODYs, where the weights represent the share of the relevant product in the country's export basket:

$$
\mathrm{EXPY}_{i}=\sum_{k}\left(\frac{x_{i k}}{X_{i}}\right) \mathrm{PRODY}_{k}=\sum_{k} \sum_{j} \frac{\left(\frac{x_{i k}}{X_{i}}\right)\left(\frac{x_{j k}}{X_{j}}\right)}{\sum_{j}\left(\frac{x_{j k}}{X_{j}}\right)}(Y / L)_{j}
$$

Having derived the equation for the economic sophistication index, $\operatorname{EXPY}_{i}$, we want to link this index with the average IQ level. Thus, following Jones and Schneider (2010), we assume the IQ-augmented Cobb-Douglas production function:

$$
Y_{j}=\left(K_{j}\right)^{a}\left(e^{\gamma \mathrm{IQ}} A_{j} L_{j}\right)^{1-a}
$$

where $j$ is the country; $Y, K, A$ and $L$ are output, the capital stock, technology, and the labor supply, respectively; $\gamma$ is the impact of IQ on human capital. Reorganizing the production function, we get:

$$
\left(\frac{Y}{L}\right)_{j}=A_{j} e^{\gamma \mathrm{IQ}_{j}}\left(\frac{K}{Y}\right)_{j}^{\frac{\alpha}{1-\alpha}}
$$

This is the equation derived by Jones and Schneider (2010) to evaluate the impact of IQ differences on steady-state living standards. As the authors argue (p. 748), writing the equation in this way is useful since in a Solow or Ramsey growth model, the steadystate capital-output ratio is independent of the level of technology and by extension, the level of IQ (see also Jones and Podemska-Mikluch 2010). The relationship between national average IQ and national productivity has been investigated empirically by Lynn and Vanhanen (2002) and Jones and Schneider (2006). The first paper finds a correlation coefficient of 0.7 between national average IQ and the level of GDP per worker in 81 countries. The respective coefficient in Jones and Schneider (2006) is 0.82 in a 455 cross-country growth regressions analysis (à la Sala-i-Martin et al. 2004).

Substituting the last equation in Eq. (3), we get:

$$
\operatorname{EXPY}_{i}=\sum_{k} \sum_{j} \frac{\left(\frac{x_{i k}}{X_{i}}\right)\left(\frac{x_{j k}}{X_{j}}\right)}{\sum_{j}\left(\frac{x_{j k}}{X_{j}}\right)}(Y / L)_{j}=\sum_{k} \sum_{j} \frac{\left(\frac{x_{i k}}{X_{i}}\right)\left(\frac{x_{j k}}{X_{j}}\right)}{\sum_{j}\left(\frac{x_{j k}}{X_{j}}\right)} A_{j} e^{\gamma \mathrm{IQ}_{j}}\left(\frac{K}{Y}\right)_{j}^{\frac{\alpha}{1-\alpha}}
$$

This is the equation that qualitatively delivers the link between IQ and steady-state sophistication of exported products. Building upon this intuition, we formulate the main hypothesis to be tested in the paper. We thus empirically test the hypothesis that two countries that differ only in average IQ-everything else being constant across countries (ceteris paribus) - manifest differences in economic sophistication. That is, if one of the two countries moves to a higher IQ level, in the steady-state, economic sophistication would be greater in the higher IQ country. 
The following section describes analytically the data and formally sets the equation to be tested which is augmented by additional controls that correlate with the measure of economic sophistication.

\section{Data and estimation strategy}

We measure economic sophistication in year 2010 using the respective value of the Economic Complexity Index (ECI) available at the MIT's Observatory of Economic Complexity (https://atlas.media.mit.edu/rankings), which is calculated according to Hidalgo and Hausmann's (2009) economic complexity formula. The ECI is a measure of diversity and sophistication of a country's export structure (Hausmann and Hidalgo 2014). The ECI captures information about an economy's level of development that is different from that captured, for example, by the measures of GDP growth or per capita GDP.

To illustrate this difference, Fig. 1 compares the product structures of the economies of Chile and Ecuador with those of Malaysia and Thailand, respectively (see also the discussion in Hartmann et al. 2017). When comparing the countries in terms of GDP per capita (source: World Development Indicators, World Bank), the economies of Chile (\$18,256 at PPT in current 2011 US\$) and Ecuador (\$9163) are similar to the economies of Malaysia $(\$ 20,675)$ and Thailand $(\$ 13,309)$, respectively, but their productive structures differ significantly. Analytically, Chile and Ecuador largely export natural resources, raw materials and agricultural products, while, in contrast, Malaysia and Thailand export a diverse spectrum of electronic parts, peripherals and accessories as well as machinery, like trucks and cars. The ECI captures these differences in productive structures, assigning higher values to the more sophisticated, diversified and complex economies of Malaysia and Thailand (in 2010, Malaysia ranked 32nd while Chile ranked 68th and Thailand ranked 28th while Ecuador ranked only 95th).

Following a series of papers mentioned in the related literature section and in Appendix [e.g., Weede and Kämpf (2002) and Hafer and Jones (2015) among others], we measure Intelligence using the IQ data by Lynn and Vanhanen (2006) and Lynn and Meisenberg (2010). In the baseline results, we use the data by Lynn and Vanhanen (2006), so as not to allow simultaneity to kick in. However, this is not crucial and in the robustness section we use the data for the year 2010, where our results remain intact.

The nature of the data is such that it does not allow exploiting any time variation. While in general it is true that when it comes to IQ scores they might evolve upward overtime this takes place over very large periods, e.g., two or three generations difference, a time span that is not covered by the existing dataset. Analytically, there are three sources of data for IQ, i.e., (a) Lynn and Vanhanen (2002) (b) Lynn and Vanhanen (2006) and (c) Lynn and Meisenberg (2010). Each dataset simply extends the previous version of the data from 81 countries that were initially published in 2001 and 2002, to 113 countries in 2006 and a total of 136 countries in 2010. Thus, any changes are related to the number of countries included in the sample and not in changes in the IQ of the existing countries. This is the reason why our study, like all the above-mentioned studies, exploits the cross-country nature of the data. 

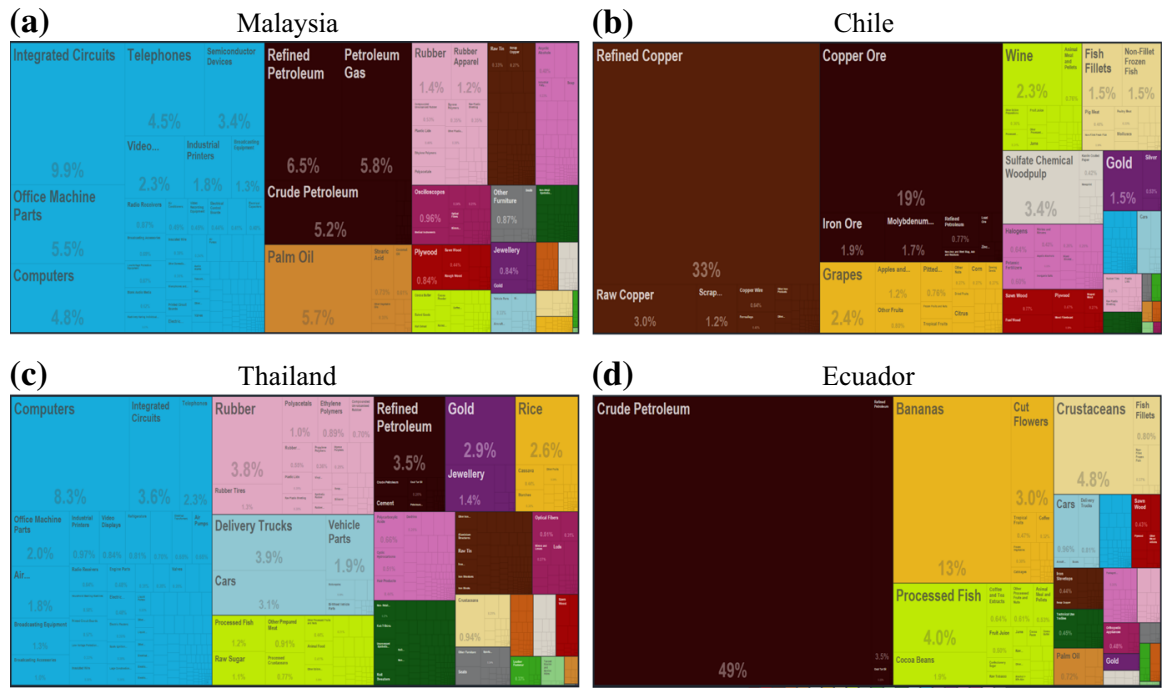

Fig. 1 (Colored) Export structure of Malaysia (a), Chile (b), Thailand (c) and Ecuador (d) in 2010. Source: https://atlas.media.mit.edu

Table A.1 in Appendix illustrates the summary statistics of the sample in the benchmark analysis, i.e., for 108 countries for which the full set of benchmark controls is available. The ECI index in our sample takes values from -2.38 to 2.10 , while the average IQ takes values from 64 to 108. It includes several low- and high-income countries. (The high values are due to the fact that we use PPP measure of GDP, essential for meaningful comparisons.) Similarly, we have a wide range of countries with respect to institutional quality that includes both democracies and dictatorships.

Figure 2 shows that Intelligence is positively associated with Sophistication with a correlation coefficient between ECI and IQ at 0.77. Countries with high IQ populations and high product sophistication include Japan, Singapore and Switzerland.

To ensure robust econometric identification, we use a number of control variables in the estimated equation. More precisely, we control for the overall level of productivity and wealth in the economy by employing real (log) GDP per capita (Log GDP per capita) from the World Bank's World Development Indicators and for the year 2010. We also control for countries' institutional differences using the Polity democracy index from the Polity IV database, for the year 2010 (Marshall and Jaggers 2002). In addition, we employ ethno-linguistic fractionalization by employing the Alesina et al. (2003) data on Ethnic Diversity and Linguistic Diversity. Finally, we employ Openness (imports plus exports as percentage of GDP for the year 2010 from the World Bank's World Development Indicators) to account for international market integration. We also include a set of Geographical dummies for Africa, Europe, Oceania, North and South America and Asia so as to capture continental differences.

Importantly, we introduce each set of controls gradually, in columns (1)-(6) of Table 1, to study the evolution of the coefficient. Controlling for GDP and Polity causes a big drop in the coefficients, a result that is anticipated as these are two very 


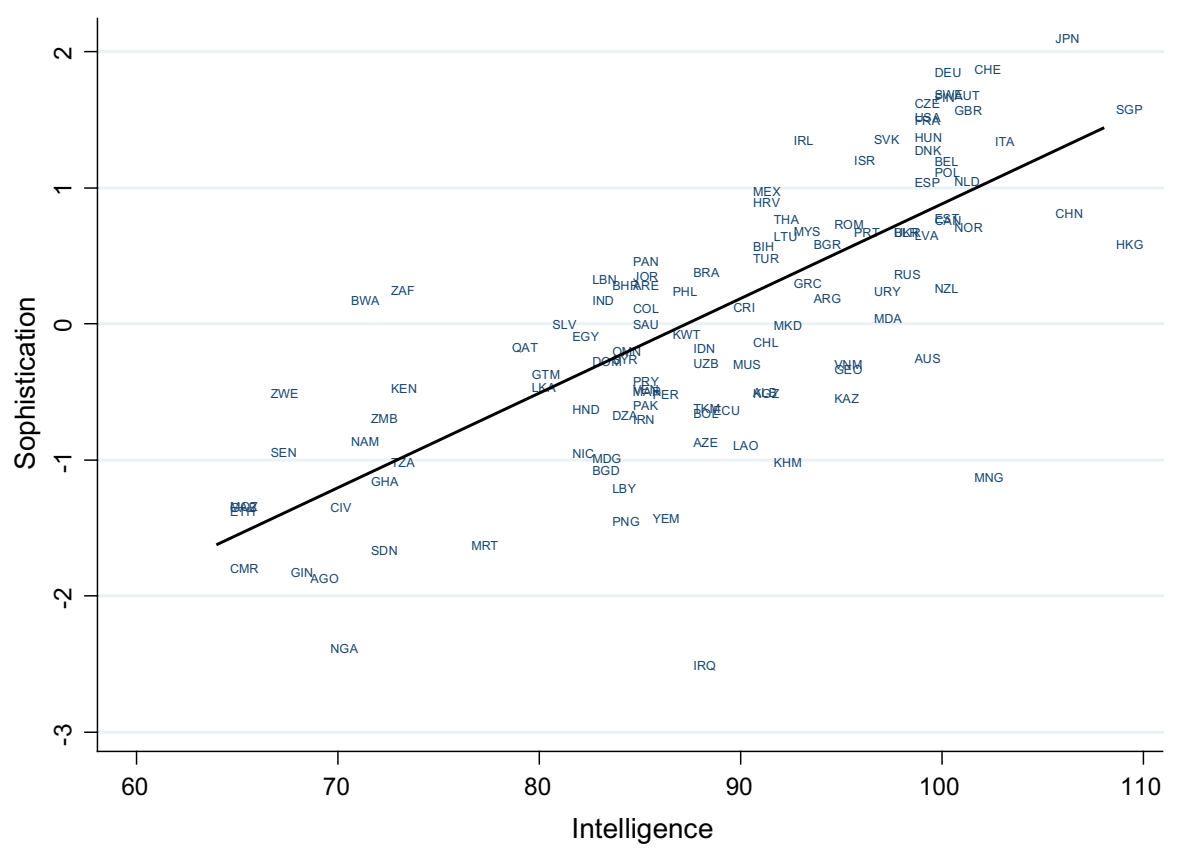

Fig. 2 Sophistication and intelligence

crucial controls that capture a large fraction of differences. Any additional controls do not significantly change the magnitude of the coefficient, thus suggesting that most of the unobserved heterogeneity has already been captured by the first two controls. This is further reinforced by the fact that the adjusted $R$-squared also remains rather constant beyond the introduction of the first two controls, even after controlling for the continental fixed effects. In line with the method suggested by Oster (2014), that takes into account both the evolution of the coefficient and of the $R$-squared, most of the unobserved heterogeneity is already captured by the two main controls. To further explore unobserved heterogeneity, we conduct another formal test suggested by Frank et al. (2013). The results of this test suggest that to invalidate our inference regarding the effect of IQ on ECI one would have to replace more than $80 \%$ of the sample in our study, and assume the limiting condition of zero effect of IQ in the replacement cases. We are thus reassured that our analysis is not plagued by unobservables.

The baseline specification used to study the relationship between Intelligence and Sophistication has the following form:

$$
\begin{aligned}
\text { Sophistication }_{i}= & \alpha_{0}+\beta_{1} \text { Intelligence }_{i}+\beta_{k} \text { controls }_{i} \\
& + \text { geographical dummies } \\
i & +u_{i}
\end{aligned}
$$


Table 1 Sophistication and intelligence: benchmark results

\begin{tabular}{|c|c|c|c|c|c|c|}
\hline $\begin{array}{l}\text { Dependent } \\
\text { variable: } \\
\text { Sophistica- } \\
\text { tion }\end{array}$ & (1) & (2) & (3) & (4) & (5) & (6) \\
\hline Intelligence & $\begin{array}{l}0.070^{* * *} \\
(0.006)\end{array}$ & $\begin{array}{l}0.047^{\text {*** }} \\
(0.008)\end{array}$ & $\begin{array}{l}0.039^{* * * *} \\
(0.007)\end{array}$ & $\begin{array}{l}0.034^{\text {*** }} \\
(0.008)\end{array}$ & $\begin{array}{l}0.033^{* * *} \\
(0.008)\end{array}$ & $\begin{array}{l}0.030^{* * *} \\
(0.010)\end{array}$ \\
\hline $\begin{array}{l}\text { Log GDP } \\
\text { per capita }\end{array}$ & & $\begin{array}{l}0.314^{* * *} \\
(0.073)\end{array}$ & $\begin{array}{l}0.329^{* * *} \\
(0.068)\end{array}$ & $\begin{array}{l}0.328^{* * * *} \\
(0.066)\end{array}$ & $\begin{array}{l}0.325^{* * *} \\
(0.068)\end{array}$ & $\begin{array}{l}0.329^{* * *} \\
(0.068)\end{array}$ \\
\hline Polity & & & $\begin{array}{l}0.032^{* * *} \\
(0.007)\end{array}$ & $\begin{array}{l}0.031^{* * *} \\
(0.007)\end{array}$ & $\begin{array}{l}0.032^{* * * *} \\
(0.007)\end{array}$ & $\begin{array}{l}0.035^{* * *} \\
(0.011)\end{array}$ \\
\hline $\begin{array}{l}\text { Ethnic } \\
\text { diversity }\end{array}$ & & & & $\begin{array}{l}-0.566^{*} \\
(0.332)\end{array}$ & $\begin{array}{l}-0.574^{*} \\
(0.329)\end{array}$ & $\begin{array}{l}-0.391 \\
(0.316)\end{array}$ \\
\hline $\begin{array}{l}\text { Linguistic } \\
\text { diversity }\end{array}$ & & & & $\begin{array}{l}0.225 \\
(0.243)\end{array}$ & $\begin{array}{l}0.192 \\
(0.251)\end{array}$ & $\begin{array}{l}0.051 \\
(0.257)\end{array}$ \\
\hline Openness & & & & & $\begin{array}{l}0.001 \\
(0.001)\end{array}$ & $\begin{array}{l}0.001 \\
(0.001)\end{array}$ \\
\hline $\begin{array}{c}\text { Geographical } \\
\text { dummies }\end{array}$ & No & No & No & No & No & Yes \\
\hline Observations & 108 & 108 & 108 & 108 & 108 & 108 \\
\hline$R$-squared & 0.603 & 0.683 & 0.726 & 0.735 & 0.737 & 0.774 \\
\hline
\end{tabular}

Robust standard errors in parentheses. The $*$, $* *$ and $* * *$ marks denote statistical significance at the 10, 5 and $1 \%$, respectively

where the subscript $i$ refers to country $i$. All regressions are estimated with Ordinary Least Squares (OLS). We also include robust standard errors to correct for heteroscedasticity. ${ }^{3}$

\section{Results}

\subsection{Basic results}

Table 1 shows the baseline results. In column (1), we simply regress Sophistication on Intelligence. The correlation coefficient is positive and highly significant (at the $1 \%$ level). This result indicates that economies characterized by higher Intelligence produce and export more sophisticated products. Column (2) introduces a control for income per capita (log). This captures large differences in income across countries as well as several qualitative differences. Indeed, as anticipated this control bears a positive and highly significant coefficient indicating that richer countries tend to produce more complex products. Moreover, the coefficient of Intelligence drops significantly, thus verifying that income per capita is an important control capturing a large fraction of the unobserved heterogeneity. Column (3) introduces Polity, a control that captures

\footnotetext{
3 Conducting the Breusch-Pagan test, we can reject the null hypothesis for homoscedasticity at the 5\% level and thus we correct for heteroscedasticity by obtaining the White-corrected robust variance estimates.
} 
institutional quality (Marshall and Jaggers 2002). The sign of the coefficient is also positive and highly significant (at $1 \%$ level), highlighting the positive effect of political institutions on a country's productive structure. This result is in line with the theory that goes back to the writings of Lewis (1954), Rostow (1959), Kuznets and Murphy (1966), Kaldor (1967), Chenery and Taylor (1968) where the development and growth of nations is viewed as a process of structural transformation of their economies' productive structure and it is recently revived and extendible emphasized by Acemoglu and Zillibotti (1999), Acemoglu and Robinson (2012), Hidalgo et al. (2007), Hidalgo and Hausmann (2009), among others. Moreover, the coefficient of Intelligence further drops, thus suggesting that institutional quality is another crucial control variable.

Column (4) introduces two measures of diversity, namely ethnic and linguistic diversity. The only measure that comes as significant is the measure of ethnic diversity which is significant at the $10 \%$ level and has a negative coefficient. This implies that higher diversity is associated with lower economic sophistication, potentially due to the fact that higher ethnic diversity is associated with lower cooperation and lower quality of institutions which can harm the productive structure of the economy. The other control is insignificant. Importantly, we observe that the coefficient of Intelligence remains relatively intact and so does the adjusted $R$-squared, which implies that most of the unobserved heterogeneity has already been captured by the previous controls introduced in columns (2) and (3). Column (5) enriches the analysis with a measure for the degree of country's openness. The coefficient is nonsignificant, and the coefficient for Intelligence remains rather stable. Last, column (6) controls for a set of continental fixed effects which should capture the large differences across continents. However, the results remain rather unchanged, and thus we are reassured that the positive effect of Intelligence on Sophistication remains even after controlling for a large number of controls and unobservables. The results in column (6) will be henceforth mentioned as the benchmark specification that accounts for the full set of controls. It should be noted that the number of observations has been stabilized to 108 countries for which we have observations for all controls. We are thus reassured that our results are not driven by changes in the sample. ${ }^{4}$

Table 2 provides some additional results that shed more light on the quantitative importance of our results. Column (1) of Table 2 replicates the analysis in column (6) of Table 1. The difference is that it reports the standardized betas. We obtain two types of information from this specification. First, the beta coefficient is 0.337 suggesting that one standard deviation change in the measure of Intelligence is associated with a 0.337 change in the standard deviation of the measure of Sophistication. To further quantify the result in terms of the actual ranking, a 10-unit change in the measure of IQ (that takes values from 64 to 108, with standard deviation 10.8) is associated with a 0.34 change in the ECI measure (that takes values from -2.4 to 2.1, with standard deviation 0.975), which is a non-trivial effect. Second, the beta coefficients allow us to compare the differential effect of each factor. Interestingly, we can see that the effect is slightly lower to that of per capita GDP (where a unitary change in the standard deviation of GDP is associated with a 0.402 change in the standard deviation of the

\footnotetext{
${ }^{4}$ From a previous version of the paper, it is clear that the results hold even for a larger set of countries. In the robustness section, we will also allow greater flexibility as to the number of countries.
} 
Table 2 Sophistication and intelligence: quantification of the results

\begin{tabular}{lll}
\hline $\begin{array}{l}\text { Dependent variable: } \\
\text { Sophistication }\end{array}$ & $(1)$ & $(2)$ \\
\hline Intelligence & $0.337^{* * *}$ & \\
& $(0.010)$ & $0.021^{* * *}$ \\
Intelligence (low-sophistication & & $(0.007)$ \\
countries) & & $0.030^{* * *}$ \\
Intelligence (high-sophistication & & $(0.007)$ \\
countries) & & $0.254^{* * *}$ \\
Log GDP per capita & $0.402^{* * *}$ & $(0.053)$ \\
& $(0.068)$ & $0.131^{* *}$ \\
Polity & $0.243^{* * *}$ & $(0.009)$ \\
Ethnic diversity & $(0.011)$ & -0.081 \\
& -0.095 & $(0.237)$ \\
Linguistic diversity & $(0.316)$ & 0.010 \\
& 0.014 & $(0.172)$ \\
Openness & $(0.257)$ & -0.014 \\
Geographical dummies & 0.011 & $(0.001)$ \\
Beta coefficients & $(0.001)$ & Yes \\
Observations & Yes & Yes \\
\hline -squared & Yes & 108 \\
& 108 & 0.857 \\
\hline
\end{tabular}

Column (1) replicates the analysis in column (6) of Table 1 and reports the standardized betas. Column (2) replicates the analysis in column (6) of Table 1, by estimating the effect separately for countries with high and low levels of product sophistication. Robust standard errors in parentheses. The *, ** and *** marks denote statistical significance at the 10,5 and $1 \%$, respectively

ECI) and stronger than the effect of institutions (where a unitary change in the standard deviation of Polity is associated with a 0.243 change in the standard deviation of the ECI).

Column (2) of Table 2 replicates the benchmark analysis by estimating the effect separately for countries with high and low levels of product sophistication. (Each group contains a similar number of countries, i.e., 50 and 58 countries, respectively.) Our findings suggest that the effect of IQ is positive and highly significant for both groups of countries. As to the magnitude of the effect, it is quite similar to that described in column (1). Interestingly, the effect is stronger for countries with high level of product sophistication, i.e., the effect of Intelligence is further reinforced in high-sophistication countries. It should be noted though that the difference is not very pronounced.

\subsection{Robustness checks}

In this section, we establish the robustness of our results to alternative specifications. 
Table 3 Sophistication and intelligence: robustness to the use of alternative ECI measures

\begin{tabular}{|c|c|c|c|}
\hline & (1) & (2) & (3) \\
\hline Intelligence & $\begin{array}{l}0.031^{* *} \\
(0.012)\end{array}$ & $\begin{array}{l}0.034^{* * *} \\
(0.009)\end{array}$ & $\begin{array}{l}0.039^{* * *} \\
(0.007)\end{array}$ \\
\hline Log GDP per capita & $\begin{array}{l}0.196^{* *} \\
(0.092)\end{array}$ & $\begin{array}{l}0.315^{* * *} \\
(0.060)\end{array}$ & $\begin{array}{l}0.227^{* * *} \\
(0.078)\end{array}$ \\
\hline Polity & $\begin{array}{l}0.054^{* * *} \\
(0.014)\end{array}$ & $\begin{array}{l}0.038^{* * *} \\
(0.010)\end{array}$ & $\begin{array}{l}0.026^{*} \\
(0.013)\end{array}$ \\
\hline Ethnic diversity & $\begin{array}{l}-0.118 \\
(0.388)\end{array}$ & $\begin{array}{l}-0.408 \\
(0.285)\end{array}$ & $\begin{array}{l}-0.685^{* *} \\
(0.287)\end{array}$ \\
\hline Linguistic diversity & $\begin{array}{l}-0.563^{* *} \\
(0.267)\end{array}$ & $\begin{array}{l}-0.078 \\
(0.232)\end{array}$ & $\begin{array}{l}0.248 \\
(0.228)\end{array}$ \\
\hline Openness & $\begin{array}{l}0.001 \\
(0.001)\end{array}$ & $\begin{array}{l}0.000 \\
(0.001)\end{array}$ & $\begin{array}{l}-0.000 \\
(0.001)\end{array}$ \\
\hline Geographical dummies & Yes & Yes & Yes \\
\hline Observations & 73 & 110 & 110 \\
\hline$R$-squared & 0.768 & 0.683 & 0.733 \\
\hline
\end{tabular}

Dependent variable: ECI in the year 2013 (column 1); updated ECI (column 2); improved ECI (ECI+) (column 3). Robust standard errors in parentheses. The *, ** and *** marks denote statistical significance at the 10,5 and $1 \%$, respectively. We estimate robust standard errors

\subsubsection{Robustness to the use of different $\mathrm{ECI}$ measures}

First, we establish the robustness of our results to the use of alternative measures of ECI. Column (1) of Table 3 uses as the dependent variable the measure of ECI in the year 2013 (last available year). In this column, we also employ the Lynn and Meisenberg (2010) IQ data. As in the benchmark specification, we use the IQ measure with a lag so as not to allow for simultaneity to kick in. Column (2) replicates the benchmark analysis by introducing an updated measure of the ECI for the year 2010. (The updated ECI dataset was downloaded from MIT's Observatory of Economic Complexity on October 2017; https://atlas.media.mit.edu/en/.) Column (3) uses the measure of ECI+ introduced in Albeaik et al. (2017a), which is a simpler metric that measures the total exports of an economy corrected by how difficult it is to export each product. Furthermore, the definition of ECI+ is equivalent to the Fitness complexity metric proposed by Tacchella et al. (2012). ${ }^{5}$ All three columns in Table 3 introduce the full set of controls used in the benchmark specification and do not restrict the sample so as to verify the results for the larger sample possible. In all three columns, our findings are robust and in line with those in the benchmark specification.

\subsubsection{Robustness to additional controls and outliers}

Table 4 establishes the robustness of the analysis to the use of additional controls so as to capture an even larger number of unobservables. Even though the benchmark

\footnotetext{
5 See the discussion in Albeaik et al. (2017a).
} 
Table 4 Sophistication and intelligence. Robustness to additional controls and outliers

\begin{tabular}{|c|c|c|c|c|c|}
\hline & (1) & (2) & (3) & (4) & (5) \\
\hline Intelligence & $\begin{array}{l}0.032^{* * *} \\
(0.012)\end{array}$ & $\begin{array}{l}0.022^{* * * *} \\
(0.008)\end{array}$ & $\begin{array}{l}0.029^{* * *} \\
(0.009)\end{array}$ & $\begin{array}{l}0.027^{* * *} \\
(0.008)\end{array}$ & $\begin{array}{l}0.041^{* * *} \\
(0.010)\end{array}$ \\
\hline $\begin{array}{l}\text { Log GDP per } \\
\text { capita }\end{array}$ & $\begin{array}{l}0.353^{* * *} \\
(0.094)\end{array}$ & $\begin{array}{l}0.347^{* * *} \\
(0.060)\end{array}$ & $\begin{array}{l}0.133 \\
(0.088)\end{array}$ & $\begin{array}{l}0.163 \\
(0.122)\end{array}$ & $\begin{array}{l}0.345^{* * *} \\
(0.065)\end{array}$ \\
\hline Polity & $\begin{array}{l}0.038^{* * *} \\
(0.011)\end{array}$ & $\begin{array}{l}0.010 \\
(0.013)\end{array}$ & $\begin{array}{l}0.014 \\
(0.013)\end{array}$ & $\begin{array}{l}0.011 \\
(0.013)\end{array}$ & $\begin{array}{l}0.048^{* * *} \\
(0.010)\end{array}$ \\
\hline $\begin{array}{l}\text { Ethnic } \\
\text { diversity }\end{array}$ & $\begin{array}{l}-0.271 \\
(0.291)\end{array}$ & $\begin{array}{l}-0.347 \\
(0.288)\end{array}$ & $\begin{array}{l}-0.285 \\
(0.271)\end{array}$ & $\begin{array}{l}-0.207 \\
(0.267)\end{array}$ & $\begin{array}{l}-0.196 \\
(0.295)\end{array}$ \\
\hline $\begin{array}{r}\text { Linguistic } \\
\text { diversity }\end{array}$ & $\begin{array}{l}0.065 \\
(0.273)\end{array}$ & $\begin{array}{l}-0.092 \\
(0.240)\end{array}$ & $\begin{array}{l}-0.118 \\
(0.213)\end{array}$ & $\begin{array}{l}-0.035 \\
(0.213)\end{array}$ & $\begin{array}{l}0.017 \\
(0.300)\end{array}$ \\
\hline Openness & $\begin{array}{l}-0.001 \\
(0.002)\end{array}$ & $\begin{array}{l}0.000 \\
(0.001)\end{array}$ & $\begin{array}{l}-0.001 \\
(0.001)\end{array}$ & $\begin{array}{l}-0.002 \\
(0.002)\end{array}$ & $\begin{array}{l}0.000 \\
(0.001)\end{array}$ \\
\hline $\begin{array}{l}\text { Secondary } \\
\text { enrollment }\end{array}$ & $\begin{array}{l}0.001 \\
(0.004)\end{array}$ & & & & \\
\hline $\begin{array}{l}\text { Tertiary } \\
\text { enrollment }\end{array}$ & $\begin{array}{l}-0.001 \\
(0.005)\end{array}$ & & & & \\
\hline $\begin{array}{l}\text { Legal Origin } \\
\text { (UK) }\end{array}$ & & $\begin{array}{l}0.697^{* * *} \\
(0.205)\end{array}$ & & $\begin{array}{l}0.385^{*} \\
(0.202)\end{array}$ & \\
\hline $\begin{array}{l}\text { Legal Origin } \\
\text { (FR) }\end{array}$ & & $\begin{array}{l}0.540^{* * *} \\
(0.170)\end{array}$ & & $\begin{array}{l}0.520^{* * *} \\
(0.192)\end{array}$ & \\
\hline $\begin{array}{l}\text { Legal Origin } \\
\quad(\mathrm{GE})\end{array}$ & & $\begin{array}{l}0.424^{* *} \\
(0.163)\end{array}$ & & $\begin{array}{l}0.234 \\
(0.172)\end{array}$ & \\
\hline $\begin{array}{l}\text { Legal Origin } \\
\text { (SC) }\end{array}$ & & $\begin{array}{l}0.623^{* *} \\
(0.255)\end{array}$ & & $\begin{array}{l}0.368 \\
(0.307)\end{array}$ & \\
\hline $\begin{array}{l}\text { Legal Origin } \\
\text { (Socialist) }\end{array}$ & & $\begin{array}{l}0.449 \\
(0.307)\end{array}$ & & $\begin{array}{l}0.289 \\
(0.304)\end{array}$ & \\
\hline KOF Index & & & $\begin{array}{l}0.026^{* * *} \\
(0.007)\end{array}$ & $\begin{array}{l}0.021^{* *} \\
(0.008)\end{array}$ & \\
\hline Shadow & & & $\begin{array}{l}0.002 \\
(0.003)\end{array}$ & $\begin{array}{l}-0.001 \\
(0.004)\end{array}$ & \\
\hline $\begin{array}{l}\text { Religious } \\
\text { diversity }\end{array}$ & & & $\begin{array}{l}0.460^{* *} \\
(0.214)\end{array}$ & $\begin{array}{l}0.087 \\
(0.239)\end{array}$ & \\
\hline $\begin{array}{l}\text { Geographical } \\
\text { dummies }\end{array}$ & Yes & Yes & Yes & Yes & Yes \\
\hline Observations & 98 & 108 & 108 & 98 & 108 \\
\hline$R$-squared & 0.801 & 0.812 & 0.825 & 0.844 & \\
\hline
\end{tabular}

Dependent variable: sophistication. Robust standard errors in parentheses. The * $* *$ and $* * *$ marks denote statistical significance at the 10,5 and $1 \%$, respectively

analysis and the works by Oster (2014) and Frank et al. (2013) suggest that unobservables do not drive the results, we introduce some additional controls here to test the robustness of our analysis.

Column (1) starts from the benchmark specification with the full set of controls and introduces two measures for secondary and tertiary education from the World Bank's 
World Development Indicators. In column (2), we include the Legal Origin dummy variables taken from La Porta et al. (1999). In column (3), we add further control variables, namely Religious Diversity from Alesina et al. (2003), the KOF Index of globalization (Dreher 2006; Dreher et al. 2008) and the size of the Shadow economy from Dreher and Schneider (2010). Adding all these controls together in column (4) leaves our empirical findings qualitatively intact.

Last, in column (5), in Table 4, we examine the robustness of our benchmark results by checking whether these are driven by individual outliers and by applying robust regression techniques. Outliers are observations that lie outside the typical relationship between the dependent and explanatory variables determined by the rest of the observations (Barnett and Lewis 1994; De Haan and Ferreira 2007). The standard practice is dropping observations identified as outliers through the residuals of the OLS estimation. However, this may in fact be inappropriate: outliers in the space of the explanatory variables (i.e. "good leverage points", Rousseeuw and Leroy 2005) are not detected by this method. In order to deal with this issue, we apply robust regression techniques. Specifically, we employ the MM-estimator (Yohai 1987). Following Rousseeuw and Yohai (1984), this class of estimators instead of minimizing the variance of the residuals (as OLS does) minimizes measures of dispersion of the residuals that are less sensitive to outliers. As can be seen in column (5), our empirical findings remain highly robust under robust regression techniques.

\subsubsection{Robustness to the use of different measures of institutional quality}

Table 5 establishes the robustness of our results to the use of alternative measures of institutional quality. In column (1), we replicate the analysis in column (6) of Table 1 just for comparison. Here, we use the measure of Polity from the Polity IV project. In column (2), we use instead the new democracy-dictatorship data from Cheibub et al. (2010). In column (3), we introduce the measure of constraints on the executives also coming from the Polity IV dataset. Last, in column (4) we use the measure of rule of law coming from the World Bank's Worldwide Governance Indicators. In all four columns, we have the full set of controls as in the benchmark specification and we simply replace the measure of institutional quality. The results remain qualitatively and quantitatively intact.

\subsection{The effect of democracy on the nexus between intelligence and sophistication}

In this subsection, we place the spotlight on the potential differential effect of the democracy on the nexus between intelligence and sophistication. To identify this channel, we alter Eq. (7) to introduce the interaction term Intelligence * Polity. We split the sample in three (column (1) of Table 6) or four (column (2) of Table 6) categories based on the Polity indicator. Each category contains a set of countries with similar political regime. This approach allows us, first, to see the interaction between institutional quality and intelligence, as well as to quantify the result for different levels of institutions. We observe that in both columns (i.e., for both types of classification of countries according to their institutional quality) the effect of intelligence becomes 
Table 5 Sophistication and intelligence. Robustness to alternative measures for institutions

\begin{tabular}{lllll}
\hline & $(1)$ & $(2)$ & $(3)$ & $(4)$ \\
\hline Intelligence & $0.030^{* * *}$ & $0.033^{* * *}$ & $0.030^{* * * *}$ & $0.028^{* * *}$ \\
& $(0.010)$ & $(0.010)$ & $(0.010)$ & $(0.010)$ \\
Polity & $0.035^{* * *}$ & & & \\
(0.011) & & & \\
$\begin{array}{l}\text { Democracy } \\
\text { (Cheibub) }\end{array}$ & & -0.001 & & \\
$\begin{array}{l}\text { Executive } \\
\text { constraints }\end{array}$ & & $(0.005)$ & $0.121^{* * *}$ & \\
Rule of law & & & $(0.034)$ & $0.392^{* * *}$ \\
Geographical & Yes & & & $(0.070)$ \\
$\quad$ dummies & 108 & Yes & Yes & Yes \\
Observations & 0.774 & 108 & 107 & 108 \\
$R$-squared & 0.754 & 0.778 & 0.795 \\
\hline
\end{tabular}

Dependent variable: sophistication. Robust standard errors in parentheses. The *,** and *** marks denote statistical significance at the 10,5 and $1 \%$, respectively

stronger as institutional quality improves. We thus find a positive nexus between intelligence and institutional quality. For instance, in column (1) the stronger effect is traced for countries that have quality of institutions higher than 6, i.e., for countries such as all EU countries but also countries like Panama, Senegal or Kenya with a good (but not perfect) quality of institutions. Similarly, for column (2), the stronger effect takes place for countries with institutional quality larger than 3 in the Polity scale, i.e., a classification that also includes countries (besides EU countries) such as Zambia, Suriname or Nigeria.

The underlying mechanism could be associated with the fact that in a wellfunctioning democracy or at least in a country with a decent level of institutions there is the necessary social and political framework that allows for the full exploitation of the benefits arising from a high average IQ at the population level. This positive "endowment" is further enriched and can be fully converted into a higher level of sophistication in the economy.

This is a very interesting result with important policy implications as it suggests that policy makers should not only aim to advance policies that raise the aggregate intelligence level but also to policies that improve institutional quality.

An additional observation is that at all levels of institutional quality, all economies can benefit from a higher level of intelligence, i.e., the positive correlation between intelligence and sophistication is valid for all regimes.

\section{Conclusions}

Our study documents a positive relationship between national estimates of cognitive skills [approximated here by the IQ series published by Lynn and Vanhanen (2006) 
Table 6 Sophistication and intelligence. Interaction with institutions

(1)

\begin{tabular}{lll}
\hline Intelligence-institutions & $0.030^{* * *}$ & \\
$(-10<$ Polity<-5) & $(0.010)$ & \\
Intelligence-institutions & $0.035^{* * *}$ & \\
$(-4<$ Polity<0) & $(0.010)$ & \\
Intelligence-institutions & $0.033^{* * *}$ & \\
$(1<$ Polity<5) & $(0.010)$ & \\
Intelligence-institutions & $0.036^{* * *}$ & \\
$(6<$ Polity<10) & $(0.010)$ & $0.030^{* * *}$ \\
Intelligence-institutions & & $(0.010)$ \\
$(-10<$ Polity<-5) & & $0.034^{* * *}$ \\
Intelligence-institutions & & $(0.010)$ \\
$(-4<$ Polity<2) & & $0.037^{* * *}$ \\
Intelligence-institutions & & $(0.011)$ \\
$(3<$ Polity<10) & & Yes \\
Geographical dummies & Yes & Yes \\
Controls & Yes & 108 \\
Observations & 108 & 0.774 \\
$R$-squared & 0.775 & \\
\hline
\end{tabular}

Dependent variable: sophistication. Robust standard errors in parentheses. The *, ** and $* * *$ marks denote statistical significance at the 10,5 and $1 \%$, respectively

and Lynn and Meisenberg (2010)] and product sophistication (using the values of the respective index from MIT's Observatory of Economic Complexity). Our paper attempts to link these two strands of literature. Our findings suggest a positive correlation between the level of a country's collective intelligence and the level of its economic sophistication. Our benchmark analysis controls for a wide set of variables and is robust to a number of alternative specifications. Our analysis is further enriched by exploring the role of democracy as a catalyst on the nexus between intelligence and sophistication.

Our findings can yield interesting policy implications. First, they hint to the fact that employing policies that can raise collective intelligence is a first-order issue as it can improve the productive capacity and level of sophistication in an economy. An example would be to increase investment in education as well as to foster qualitative changes in education that advance creativity and can thus contribute to raising collective intelligence. For instance, it has been shown that at the individual level, one extra year of schooling can increase IQ by 1.5-2 units.

Second, they highlight another dimension along which well-functioning institutions can contribute to a country's overall efficiency. Improving institutional quality can operate via several distinct channels one of which is improving the level of the economy's product sophistication. Product sophistication reflects among other things the ability to create and document information. A typical example would be property rights and the associated incentives to develop innovative products. It is self-evident 
that living in a regime with good-quality institutions greatly enlarges the possibility to create and develop new information/knowledge and thus to raise the economy's level of sophistication.

Overall, by bringing together these two strands of literature we aspire to link the interesting measure of complexity to the economics literature and to contribute one more determinant that can enhance the level of sophistication of the economy.

Acknowledgements We would like to thank Antonios Garas for constructive suggestions. We also thank the editor of the journal and three anonymous referees for valuable comments. Any remaining errors are ours. The final revisions of both text and empirical strategy of the article have been conducted when Athanasios Lapatinas took service at the European Commission, Joint Research Centre. The scientific output expressed does not imply a policy position of the European Commission. Neither the European Commission nor any person acting on behalf of the Commission is responsible for the use, which might be made of this publication.

Open Access This article is distributed under the terms of the Creative Commons Attribution 4.0 International License (http://creativecommons.org/licenses/by/4.0/), which permits unrestricted use, distribution, and reproduction in any medium, provided you give appropriate credit to the original author(s) and the source, provide a link to the Creative Commons license, and indicate if changes were made.

\section{References}

Acemoglu D, Robinson JA (2012) Why nations fail: the origins of power, prosperity and poverty. Crown Publishers, New York

Acemoglu D, Zilibotti F (1999) Information accumulation in development. J Econ Growth 4:5-38

Albeaik S, Kaltenberg M, Alsaleh M, Hidalgo CA (2017a) Measuring the knowledge intensity of economies with an improved measure of economic complexity. arXiv preprint arXiv:1707.05826

Albeaik S, Kaltenberg M, Alsaleh M, Hidalgo CA (2017b) 729 new measures of economic complexity (Addendum to improving the economic complexity index). arXiv preprint arXiv:1708.04107

Alesina A, Devleeschauwer A, Easterly W, Kurlat S, Wacziarg R (2003) Fractionalization. J Econ Growth 8:155-194

Barber N (2005) Educational and ecological correlates of IQ: a cross-national investigation. Intelligence 33:273-284

Barnett V, Lewis T (1994) Outliers in statistical data. Wiley, New York

Caldarelli G, Cristelli M, Gabrielli A, Pietronero L, Scala A, Tacchella A (2012) A network analysis of countries' export flows: firm grounds for the building blocks of the economy. PLoS ONE 7(10):e47278

Cheibub JA, Gandhi J, Vreeland JR (2010) Democracy and dictatorship revisited. Publ Choice 143(1-2):67-101

Chenery HB, Taylor L (1968) Development patterns: among countries and over time. Rev Econ Stat 4:391-416

Cristelli M, Tacchella A, Pietronero L (2015) The heterogeneous dynamics of economic complexity. PLoS ONE 10:e0117174

De Haan L, Ferreira A (2007) Extreme value theory: an introduction. Springer, Berlin

Dickerson RE (2006) Exponential correlation of IQ and the wealth of nations. Intelligence 34:291-295

Dreher A (2006) Does globalization affect growth? Evidence from a new index of globalization. Appl Econ 38:1091-1110

Dreher A, Schneider F (2010) Corruption and the shadow economy: an empirical analysis. Publ Choice 144:215-238

Dreher A, Gaston N, Martens P (2008) Measuring globalisation: gauging its consequences. Springer, Berlin

Felipe J, Kumar U, Abdon A, Bacate M (2012) Product complexity and economic development. Struct Change Econ Dyn 23:36-68

Frank KA, Maroulis S, Duong MQ, Kelcey B (2013) What would it take to change an inference? Using Rubin's causal model to interpret the robustness of causal inferences. Educ Eval Policy Anal 35:437-460 
Hafer R, Jones G (2015) Are entrepreneurship and cognitive skills related? Some international evidence. Small Bus Econ 44:283-298

Hartmann D, Guevara M, Jara-Figueroa C, Aristarán M, Hidalgo CA (2017) Linking economic complexity, institutions and income inequality. World Dev 93:75-93

Hausmann R, Hidalgo CA (2014) The atlas of economic complexity: mapping paths to prosperity. MIT Press, Cambridge

Hausmann R, Hwang J, Rodrik D (2007) What you export matters. J Econ Growth 12:1-25

Hidalgo CA (2015) Why information grows: the evolution of order, from atoms to economies. Basic Books, New York

Hidalgo CA, Hausmann R (2009) The building blocks of economic complexity. PNAS 106:10570-10575

Hidalgo CA, Klinger B, Barabási AL, Hausmann R (2007) The product space conditions the development of nations. Science 317:482-487

Jones G (2011) National IQ and national productivity: the hive mind across Asia. Asian Dev Rev 28:51-71

Jones G, Podemska-Mikluch M (2010) IQ in the utility function: cognitive skills, time preference, and cross-country differences in savings rates. GMU Working Paper in Economics No. 11-17. Available at SSRN: https://ssrn.com/abstract=1801566 or http://dx.doi.org/10.2139/ssrn.1801566

Jones G, Schneider WJ (2006) Intelligence, human capital, and economic growth: a Bayesian averaging of classical estimates (BACE) approach. J Econ Growth 11:71-93

Jones G, Schneider WJ (2010) IQ in the production function: evidence from immigrant earnings. Econ Inq 48:743-755

Kaldor N (1967) Strategic factors in economic development

Kanazawa S (2009) IQ and the values of nations. J Biosoc Sci 41:537-556

Kanyama IK (2014) Quality of institutions: does intelligence matter? Intelligence 42:44-52

Kodila-Tedika O, Asongu SA (2015) The effect of intelligence on financial development: a cross-country comparison. Intelligence 51:1-9

Kodila-Tedika O, Bolito-Losembe R (2014) Poverty and intelligence: evidence using quantile regression. Econ Res Guard 4:25

Kuznets S, Murphy JT (1966) Modern economic growth: rate, structure, and spread. Yale University Press, New Haven

La Porta R, Lopez-de-Silanes F, Shleifer A, Vishny R (1999) The quality of government. J Law Econ Organ 15:222-279

Lewis WA (1954) Economic development with unlimited supplies of labour. Manch Sch 22:139-191

Lynn R, Meisenberg G (2010) National IQs calculated and validated for 108 nations. Intelligence 38:353-360

Lynn R, Vanhanen T (2002) IQ and the wealth of nations. Greenwood Publishing Group, Westport

Lynn R, Vanhanen T (2006) IQ and global inequality. Washington Summit Publishers, Augusta

Marshall MG, Jaggers K (2002) Polity IV project: political regime characteristics and transitions, 1800-2002

Meisenberg G (2004) Talent, character, and the dimensions of national culture. Mank Q 45:123

Meisenberg G (2009) Wealth, intelligence, politics and global fertility differentials. J Biosoc Sci 41:519-535

Meisenberg G (2012) National IQ and economic outcomes. Pers Indiv Differ 53:103-107

Oster E (2014) Unobservable selection and coefficient stability: theory and evidence. University of Chicago Booth School of Business Working Paper

Potrafke N (2012) Intelligence and corruption. Econ Lett 114:109-112

Ram R (2007) IQ and economic growth: further augmentation of Mankiw-Romer-Weil model. Econ Lett 94:7-11

Reeve CL (2009) Expanding the g-nexus: further evidence regarding the relations among national IQ, religiosity and national health outcomes. Intelligence 37:495-505

Rindermann H (2008a) Relevance of education and intelligence at the national level for the economic welfare of people. Intelligence 36:127-142

Rindermann H (2008b) Relevance of education and intelligence for the political development of nations: democracy, rule of law and political liberty. Intelligence 36:306-322

Rindermann H (2012) Intellectual classes, technological progress and economic development: the rise of cognitive capitalism. Pers Indiv Differ 53:108-113

Rodrik D (2006) What's so special about China's exports? China World Econ 14:1-19

Rostow WW (1959) The stages of economic growth. Econ Hist Rev 12:1-16

Rousseeuw PJ, Leroy AM (2005) Robust regression and outlier detection. Wiley, New York 
Rousseeuw P, Yohai V (1984) Robust regression by means of S-estimators. In: Robust and nonlinear time series analysis. Springer, Berlin, pp 256-272

Sala-i-Martin X, Doppelhofer G, Miller RI (2004) Determinants of long-term growth: a Bayesian averaging of classical estimates (BACE) approach. Am Econ Rev 94:813-835

Saviotti PP, Frenken K (2008) Export variety and the economic performance of countries. J Evol Econ 18:201-218

Stolarski M, Jasielska D, Zajenkowski M (2015) Are all smart nations happier? Country aggregate IQ predicts happiness, but the relationship is moderated by individualism-collectivism. Intelligence 50:153-158

Tacchella A, Cristelli M, Caldarelli G, Gabrielli A, Pietronero L (2012) A new metrics for countries' fitness and products' complexity. Sci Rep 2:723

Templer DI (2008) Correlational and factor analytic support for Rushton's differential K life history theory. Pers Individ Differ 45:440-444

Vinogradov E, Kolvereid L (2010) Home country national intelligence and self-employment rates among immigrants in Norway. Intelligence 38:151-159

Weede E, Kämpf S (2002) The impact of intelligence and institutional improvements on economic growth. Kyklos 55:361-380

Yohai VJ (1987) High breakdown-point and high efficiency robust estimates for regression. Ann Stat 15:642-656 